\title{
Late Onset Brain Anomalies: Tumors, Cysts and Hemorrhages
}

Vincenzo D’Addario, Pasquale Capuano, Grazia Volpe

\begin{abstract}
Most fetal brain anomalies can be diagnosed during the second trimester scan performed to screen for fetal malformations. However; there are some cerebral pathologies which become evident only during the late second and third trimester of pregnancy. Occupying space lesions, such as tumors, cysts, vascular malformations and hemorrhages frequently appear as late onset complications in a fetus diagnosed as normal during the second trimester anomaly scan.

In this review paper the sonographic patterns of these anomalies will be described. Particular attention will be paid to the prognosis, which is extremely variable, ranging from the lethal outcome of huge brain tumors, to severe neurological handicap of severe hemorrhages or leukomalacic cysts, to normal postnatal outcome of some arachnoid cysts.
\end{abstract}

Keywords: Brain tumors, Brain cysts, Brain hemorrhages, Fetus, Ultrasound.

How to cite this article: D'Addario V, Capuano P, Volpe G. Late Onset Brain Anomalies: Tumors, Cysts and Hemorrhages. Donald S choolJ Ultrasound Obstet Gynecol 2013;7(4):484-491.

\section{Source of support $\mathrm{Nil}$}

Conflict of interest: None declared

\section{INTRODUCTION}

Ultrasonic screening of fetal brain anomalies is normally performed during the second trimester 'anomaly' scan. The sensitivity reported in different studies in recognizing central nervous system malformations ranges from 68.3 to $92.1 \%$. The Eurofetus, which is a multicentric prospective study performed in 61 European obstetric units, reports a sensitivity of $88.3 \% .{ }^{1}$ However, the fetal brain undergoes complex developmental events during the third trimester and some pathological conditions usually appears late in pregnancy. ${ }^{2}$ In this group of late onset brain anomalies tumors, cysts and hemorrhages are included.

The aim of this paper is to review the ultrasonic appearance and the clinical consequences of fetal brain tumors, cysts and hemorrhages.

\section{BRAIN TUMORS}

Congenital brain tumors are extremely rare events. Their incidence is reported to be 3.6 to 4.1 per 100,000 births. $^{3}$ They represent only 0.5 to $1.5 \%$ of all tumors detected during childhood ${ }^{4}$ and carry a very poor prognosis with a survival rate at 1 year of only $7 \%$. These tumors are not entirely the same as those found later in life. Their location, biologic behavior and histologic types are different.
They are more frequently located in the supratentorial space. The most common type of congenital brain tumor is teratoma representing $53.9 \%$ of all cases, followed by glial tumors (glioblastomas, astroblastomas, spongioblastomas) (14.6\%), lipoma (9\%), choroid plexus papilloma (7.9\%), craniopharyngioma (5.6\%), primitive neuroectodermal tumor (PNET) (2.2\%), other types (6.7\%).

\section{Ultrasonic Diagnosis}

UItrasound and, more recently, MRI have significantly contributed to the prenatal diagnosis of such a rare anomaly. The sonographic patterns of fetal brain tumors change according to the histologic type.

Teratoma is usually located in the supratentorial space and appears as complex mass with solid and cystic areas and with irregular borders. The tumor may undergo quick growth and reach huge size causing distortion of the brain and sometimes also of the face anatomy. It may present calcifications and frequently a rich vascularization at color Doppler $^{5-8}$ (Fig. 1). Sometimes teratomas may undergo cystic degeneration as a consequence of intratumoral hemorrhage and infarction, thus assuming the appearance of a multicystic lesion (Fig. 2).

PNET, astrocitomas and craniopharyngiomas show sonographic patterns similar to teratomas.

Fetal glial tumors usually present as diffusely hyperechoic masses similar to large hemorrhage or hemorrhagic infarction.

Choroid plexus papilloma appears as a hyperechoic mass inside a dilated lateral ventricle ${ }^{9}$ (Fig. 3); the ventriculomegaly is secondary to the hyperproduction of cerebrospinal fluid (CSF).

Lipomas are mainly located in the area of the corpus callosum and are hyperechoic with a typical curvilinear shape in the sagittal section ${ }^{10}$ (Fig. 4). H owever, in rare cases it may have a nodular appearance.

It is not possible to diagnose correctly the histological type of the brain tumor particularly in cases of teratomas, glial tumors, PNETs and craniopharyngiomas. In a previous experience we were able to make the correct diagnosis in only $57 \%$ of the cases. ${ }^{11}$

Huge brain tumors are responsible of macrocrania, which is present in $79 \%$ of the cases (Fig. 5). Ventriculomegaly may develop as a consequence of the obstruction of liquoral 


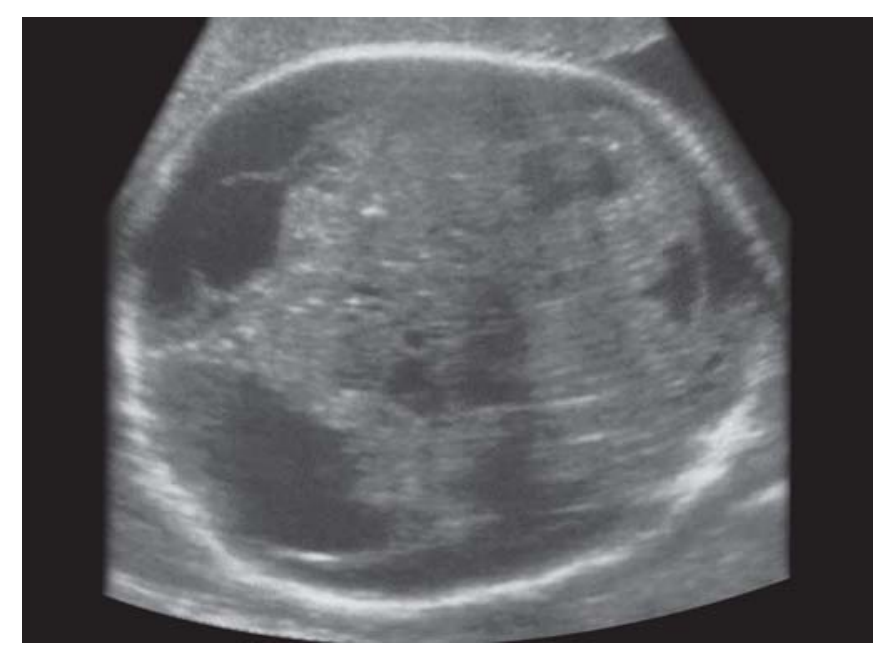

Fig. 1: Brain teratoma appearing as a huge echogenic intracranial mass with irregular borders

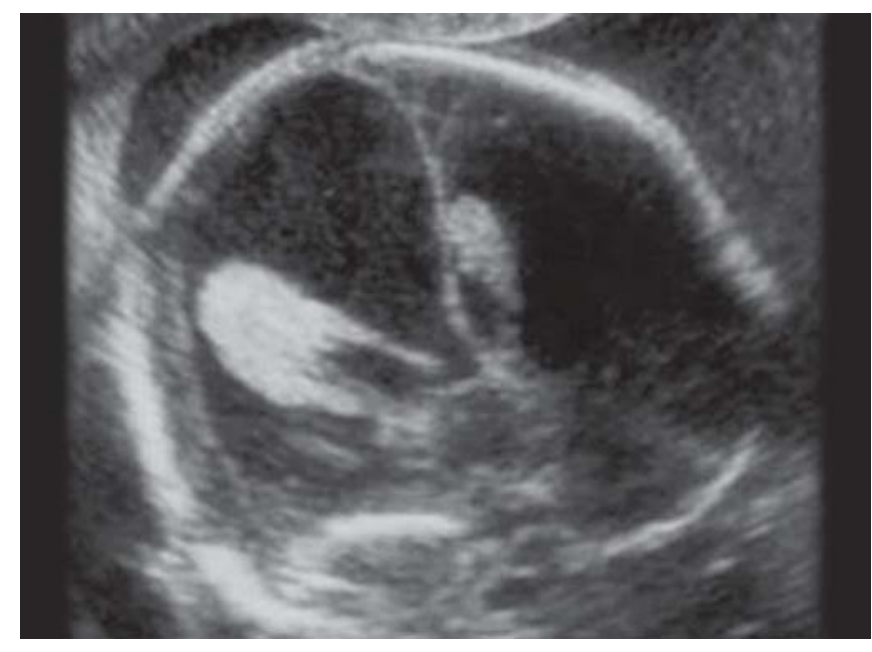

Fig. 3: Choroid plexus papilloma appearing as a hyperechoic mass inside a dilated lateral ventricle

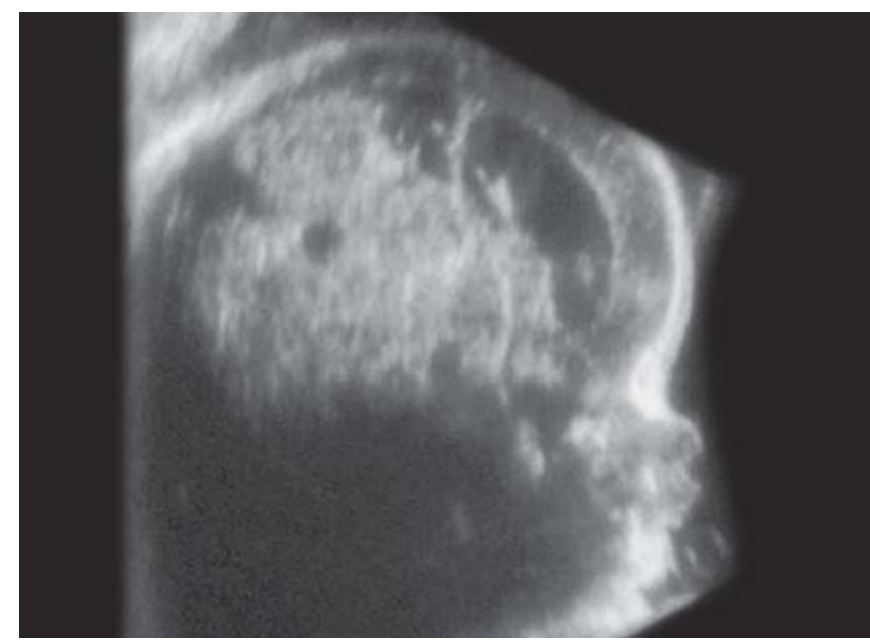

Fig. 5: Macrocrania secondary to a huge intracranial teratoma

circulation in $58 \%$ of the cases (Fig. 6). Polyhydramnios is present in $37 \%$ of the cases; one of the causes for polyhydramnios might be the presence of fetal diabetes

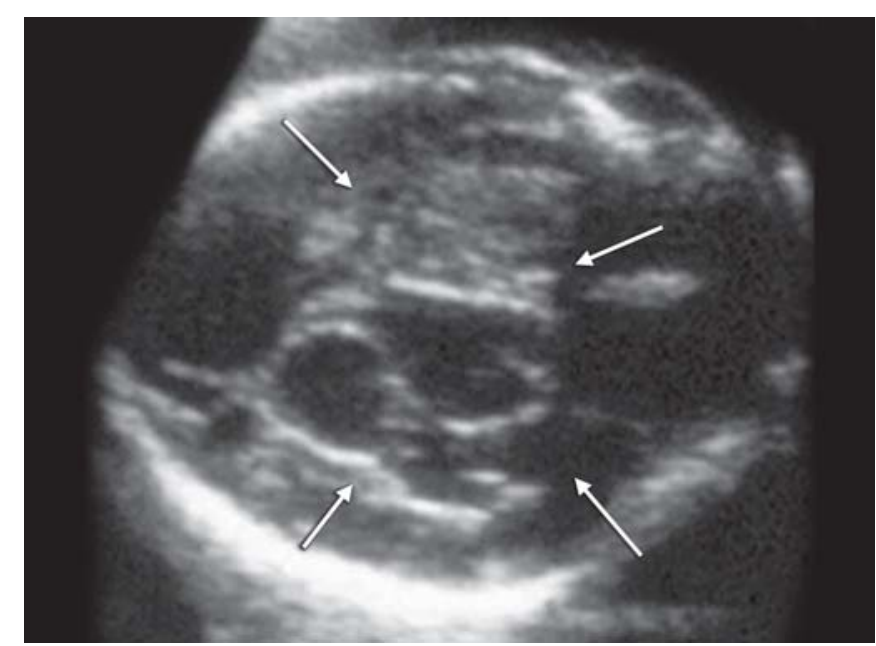

Fig. 2: Brain tumor with a multicystic appearance as a consequence of intratumoral infarctions

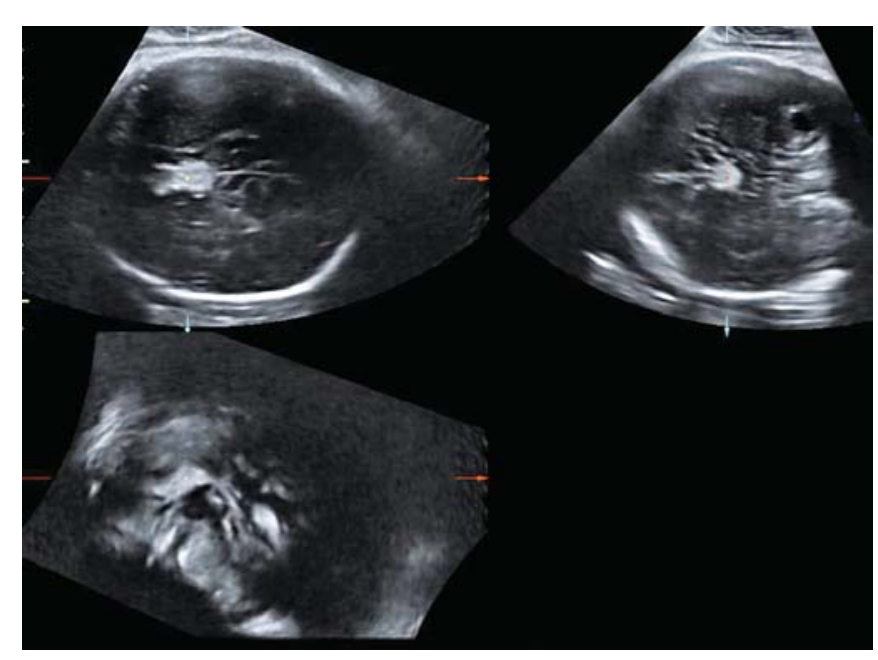

Fig. 4: 3D multiplanar view of a lipoma of the corpus callosum

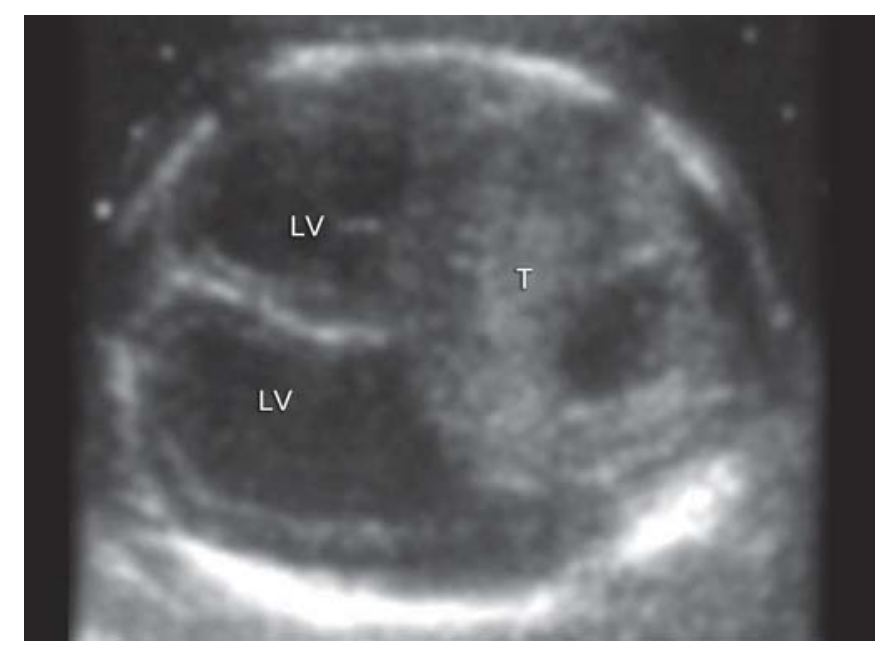

Fig. 6: Ventriculomegaly associated with intracranial tumor (T: tumor; LV: lateral ventricles)

insi pidus as a consequence of the direct compression exerted by the tumor on the hypothalamic-hypophyseal axis; another possibility could be the altered swallowing of amniotic fluid 


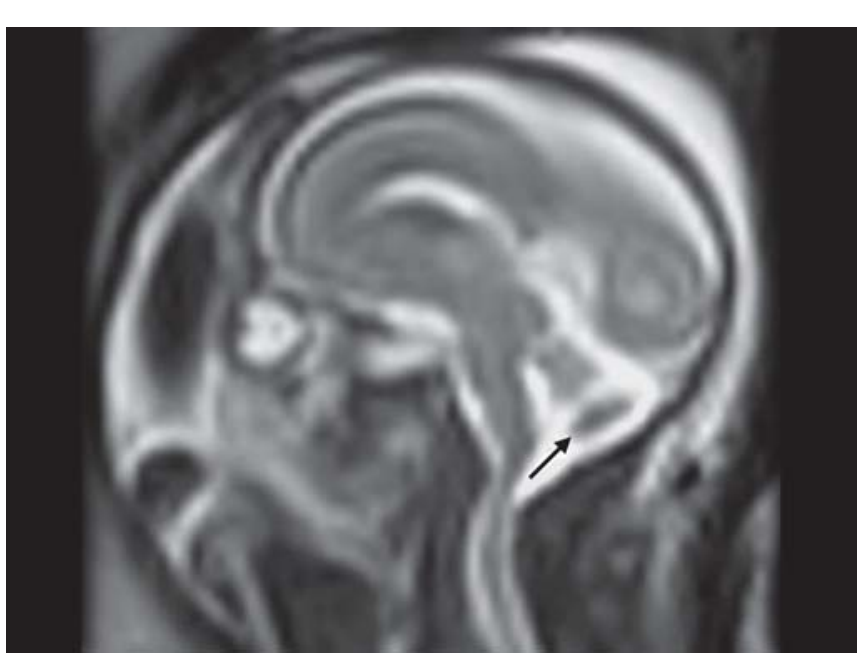

Fig. 7: MRI of the brain showing a small solid tumor in the posterio fossa below the normal cerebellar vermis, which proved to be a dermoid tumor

because of the compression of the tumor on the brain stem. In cases of huge high vascularized tumors cardiac failure and subsequent hydrops may develop.

\section{Prognosis}

The prognosis of congenital brain tumor is extremely poor particularly in cases of teratomas and PNETs in which much of the brain may be replaced by the tumor mass. The survival rate at 1 year of life is only $7 \%$ and falls to $3 \%$ in cases diagnosed before 30 weeks of gestation. The outcome is better in cases of lipomas of the corpus callosum or in cases of isolated resectable masses (Fig. 7).

\section{BRAIN CYSTS}

A ccording to their location brain cysts may be differentiated into two main subgroups: extra-axial cysts and periventricular cysts.

\section{Extra-axial Cysts}

These cysts are also known as arachnoid cysts. They are benign cystic collection of CSF in the space between the pia mater and the inner layer of the arachnoid (subarachnoid) or between the two layers of the arachnoid (intraarachnoid). ${ }^{12}$ Since, it is not possible to determine exactly the location of the fluid collection the generic term of arachnoid cyst is used. They are usually sporadic and isolated lesions, representing $1 \%$ of all neonatal nontraumatic intracranial masses. They may be primitive or secondary to adhesions by infections, hemorrhage and trauma.

As regards to their location, they are mainly supratentorial: $50 \%$ of the cases are located in the middle fossa, 5 to $10 \%$ in the suprasellar cistern, 5 to $10 \%$ in the quadrigeminal cistern, $5 \%$ along the convexities, 5 to $10 \%$ in the posterior fossa.

\section{Ultrasound Diagnosis}

In $55 \%$ of the cases the diagnosis is made between 20 and 30 weeks of gestation; in $45 \%$ after 30 weeks. They appear as thin-walled uni- or multilocular cystic masses of variable size located in different parts of the brain (Figs 8A and B). There is no communication with the ventricular cavities. $V$ entriculomegaly may be associated as a consequence of obstruction to the liquoral circulation mainly at the level of the aqueduct of Sylvius. However; there is no correlation between the cyst size and ventriculomegaly. Huge cysts cause displacement but not destruction of the surrounding brain structures ${ }^{13}$ (Figs 9A and B). The midsagittal view of the fetal brain is useful to correctly locate the small interhemispheric cysts, thus allowing to differentiate quadrigeminal cistern cysts, ${ }^{14}$ cavum veli interpositi cysts ${ }^{15}$ and suprasellar cysts $^{16}$ (Figs $10 \mathrm{~A}$ to $\mathrm{C}$ ).
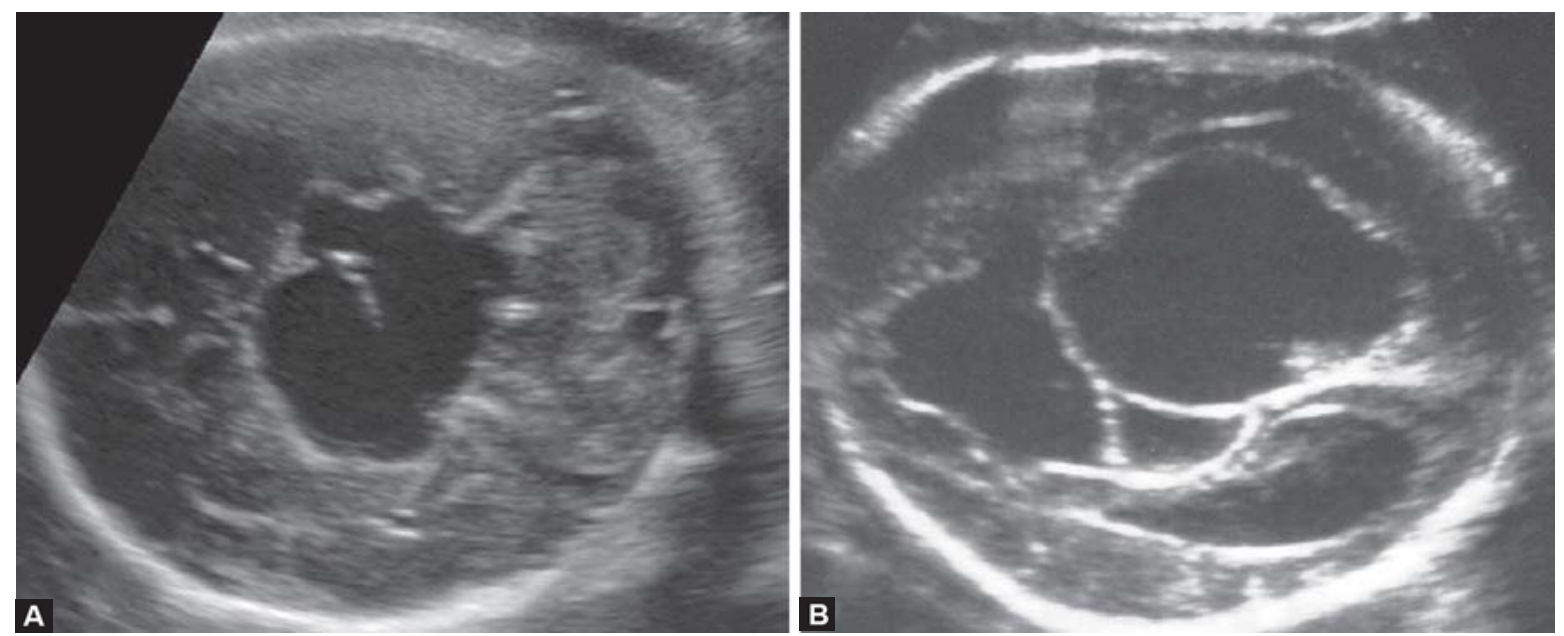

Figs 8A and B: Unilocular (A) and multilocular (B) arachnoid cysts 


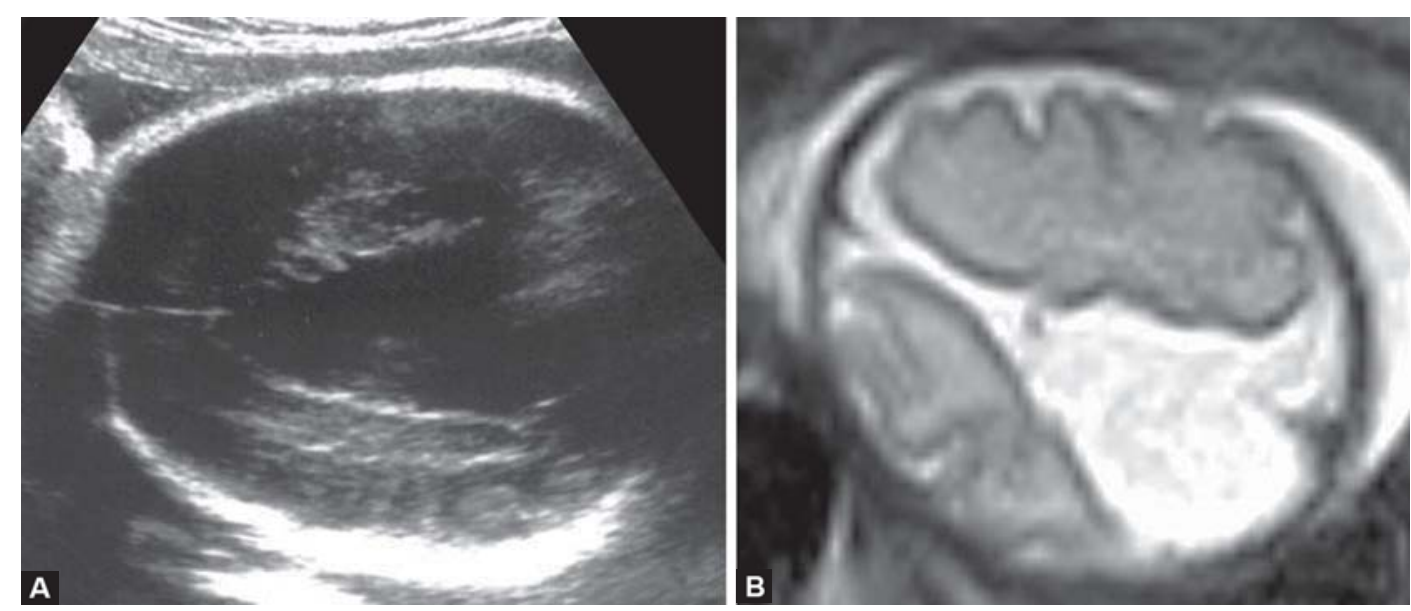

Figs 9A and B: Ultrasound and MRI of a huge interhemispheric cyst displacing the cerebral hemispheres
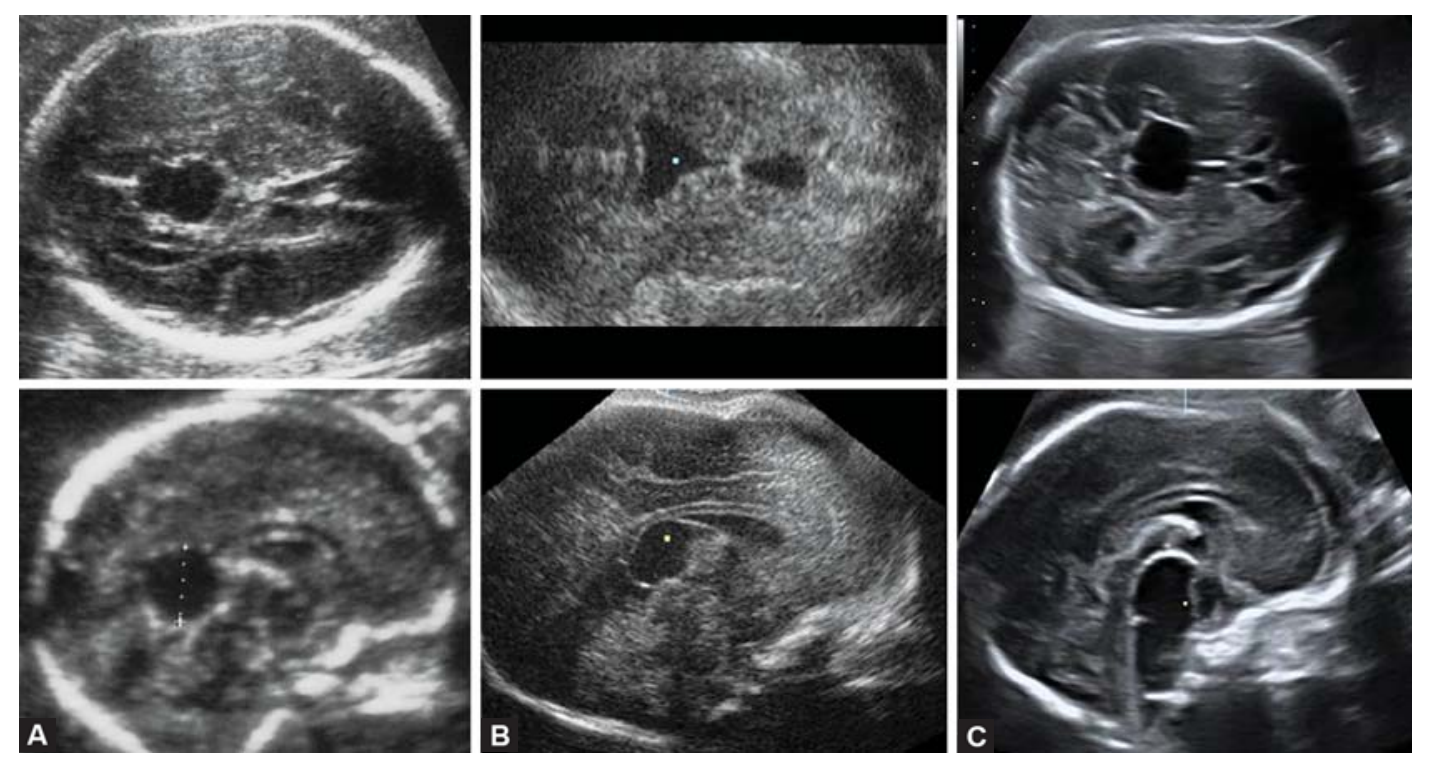

Figs 10A to C: Interhemispheric cysts in axial and sagittal views: (A) quadrigeminal cistern cyst, (B) velum interpositum cyst, (C) suprasellar cyst

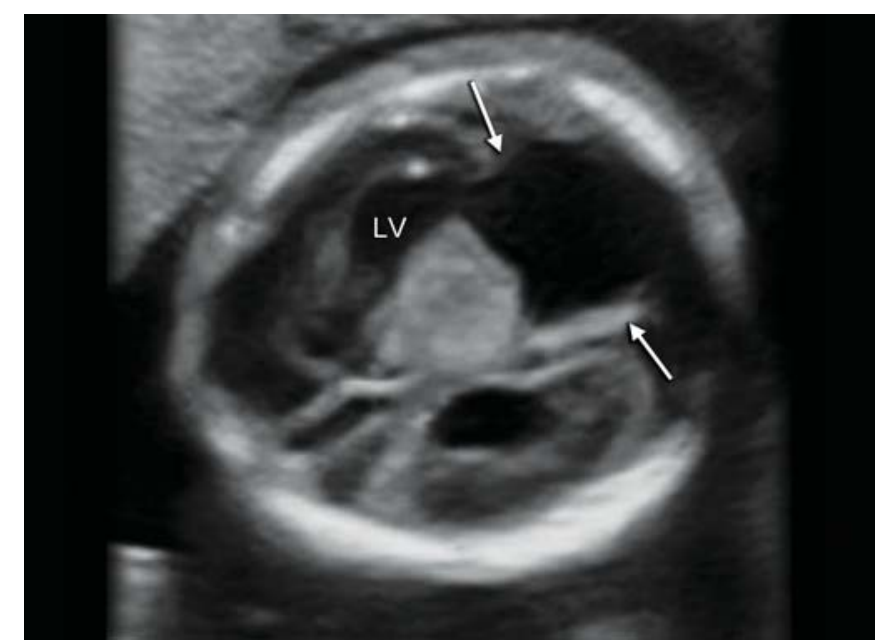

Fig. 11: Porencephalic cysts: the cyst is inside the brain parenchyma and communicates with a dilated lateral ventricle

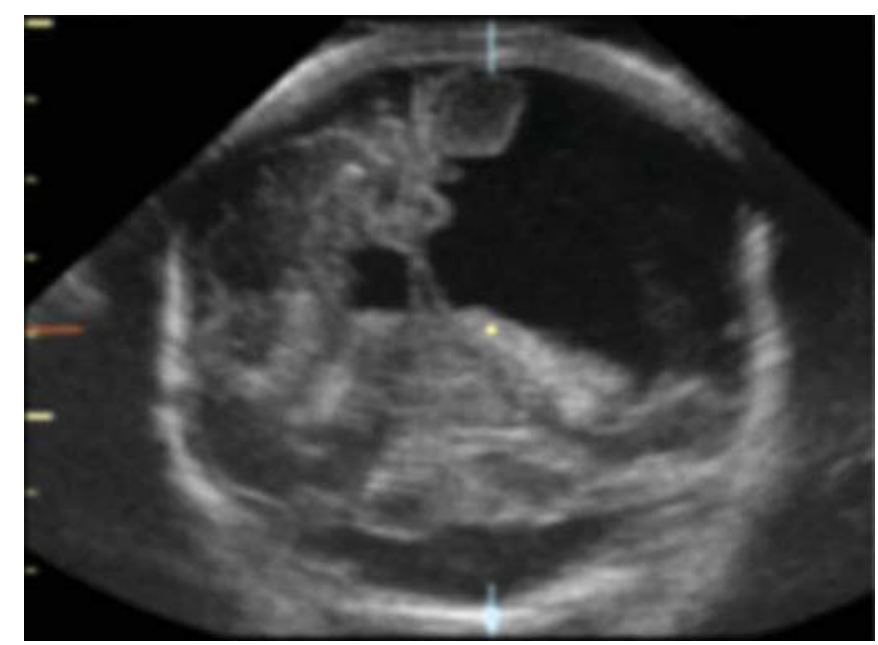

Fig. 12: Schizencephaly: there is a lack of brain tissue between the lateral ventricle and the subarachnoid space 

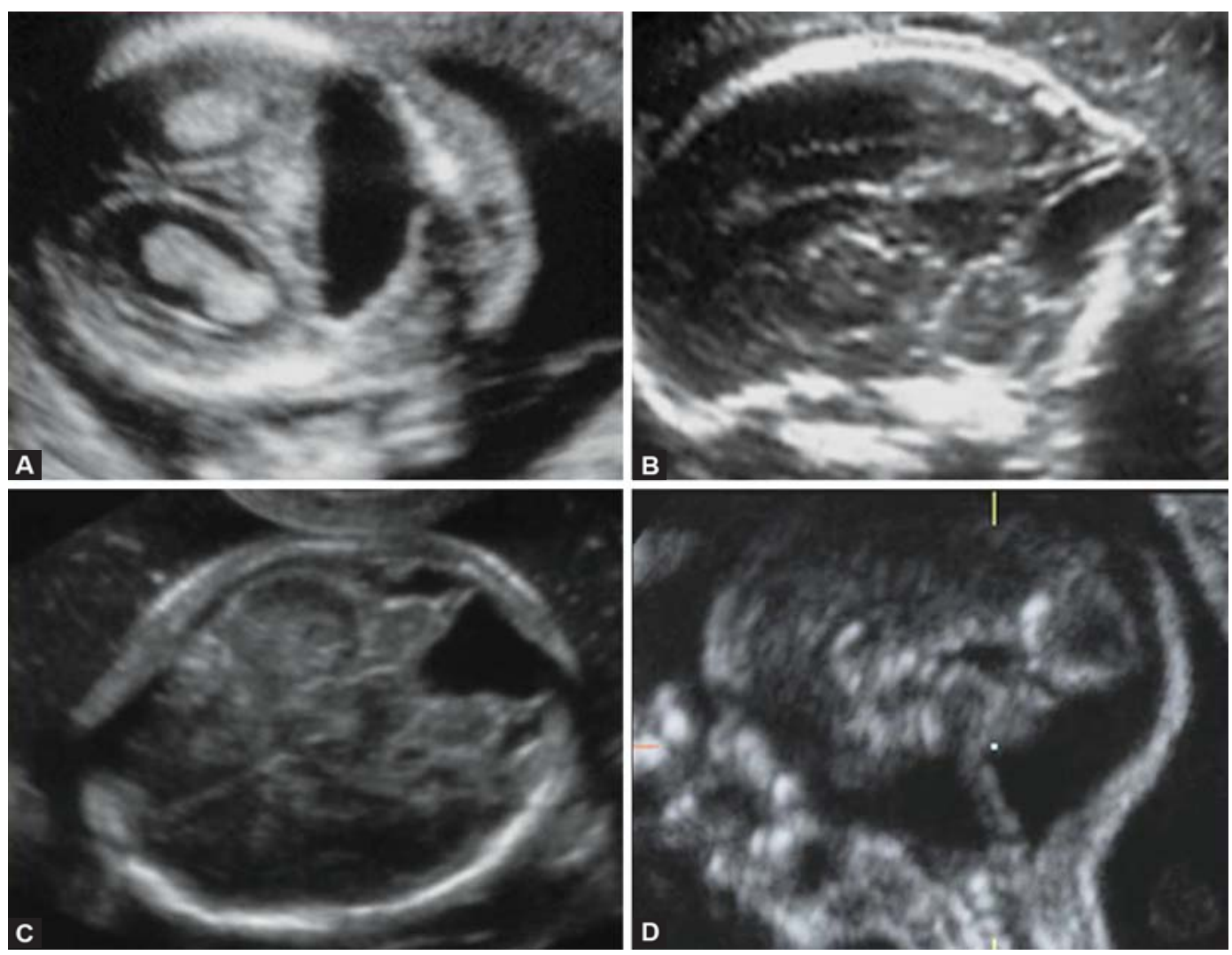

Figs 13A to D: Posterior fossa arachnoid cyst (A: axial view; B: midsagittal view) compared with a Dandy-Walker malformation (C: axial view; D: midsagittal view). In the former case the normal vermis is displaced by the cyst; in the latter a vermian defect is present

The differential diagnosis include: porencephalic cysts, schizencephaly, cystic tumors. Porencephalic cysts may be primitive or secondary to infections or vascular accidents; they are usually located inside the brain parenchyma and may communicate with the ventricular cavities (Fig. 11). Schizencephaly may be a sign of neuronal migration disorder or may be secondary to a vascular accident; ultrasonically there is a lack of brain tissue between the lateral ventricle and the subarachnoid space (Fig. 12). The rare cystic tumors have irregular borders and are located inside the brain parenchyma. Posterior fossa arachnoid cysts must be differentiated from the Dandy-Walker malformation: in this case the midsagittal view of the posterior fossa will show the vermian defect (Figs 13A to D). ${ }^{17}$

\section{Prognosis}

The natural history of arachnoid cysts is variable: some of them may increase in size during gestation; other decrease or even disappear in utero or after delivery. ${ }^{18}$ Resolution in utero is rare $(3.7 \%)$, it is more frequent after delivery (23.9\%). The possible causes of resolution are: spontaneous rupture of the thin cyst walls with leakage of the fluid in the subarachnoid space or difference in osmotic pressure between cyst and subdural space.
The postnatal outcome is independent from the size and location of the cyst, but mainly depends on the integrity of the surrounding cerebral structures. In most cases, however the prognosis is good and surgery is needed only in symptomatic cases (headache, seizure, facial neurological signs) or in case of progressive growth of the cysts.

\section{Periventricular Cysts}

Also defined as subependymal these cysts or pseudocysts are usually located at the level of the germinal matrix below the frontal horns of the lateral ventricles. They usually appear after 25 to 26 weeks of gestation. They may be single or multiple, uni- or bilateral, usually of small size (few mm) and completely anechoic (Fig. 14).

These pseudocysts may be the natural evolution of a small subependymal hemorrhage, the consequence of an hypoxic-ischemic event, or may be the result of postinfectious germinolysis caused by neurotropic viruses (CMV , rubeovirus). They may also be present in cases of genetic disorders such as Zellweger syndrome. ${ }^{19}$ In a high percentage of cases, however, they have no clinical consequence and may regress spontaneously in utero or after delivery. ${ }^{20}$ 


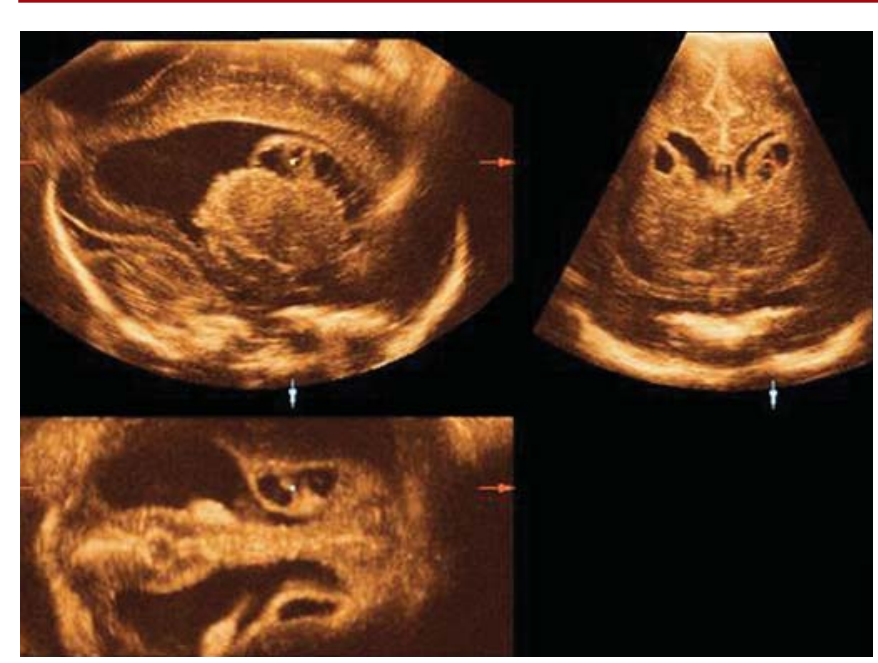

Fig. 14: 3D multiplanar view of multiple small subependymal cysts located below the frontal horns

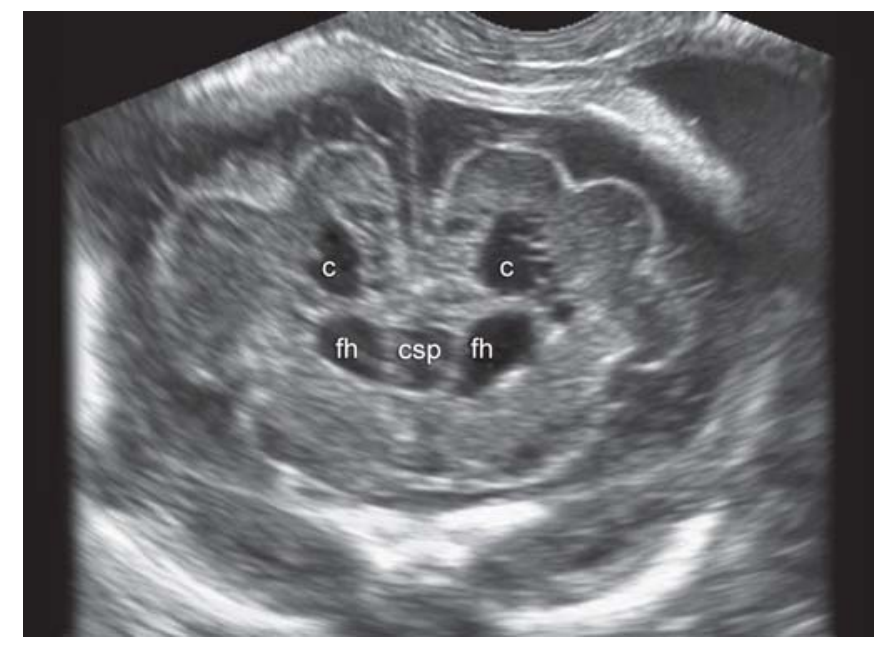

Fig. 15: Bilateral cystic periventricular leukomalacia: the cysts are located in the white matter above the frontal horns (c: cyst; fh: fh; csp: cavum septi pellucidi)
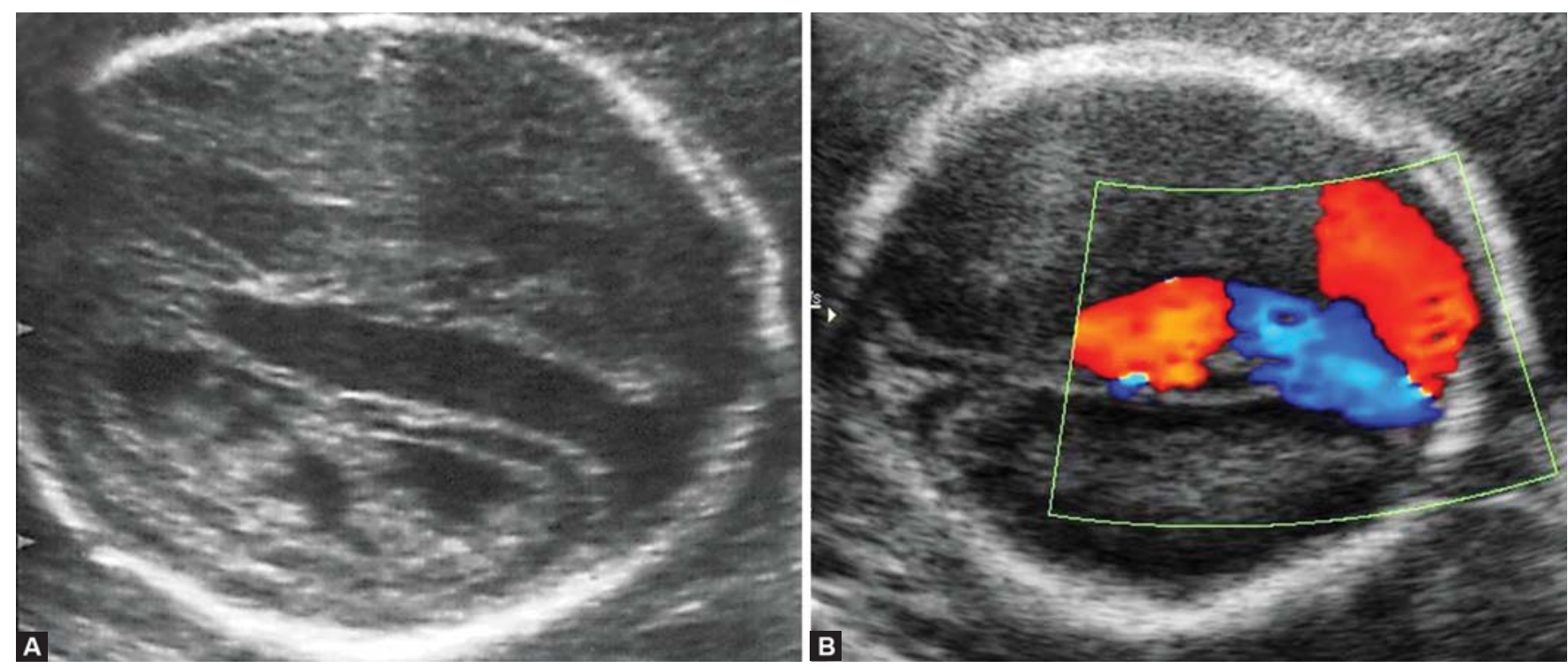

Figs 16A and B: Vein of Galen aneurysmatic malformation (VGAM): it appears as a supratentorial tubular anechoic structure located in the midline above the cerebellum (A). The color Doppler shows a typical turbulent flow (B)

The differential diagnosis is to be made with the cystic periventricular leukomalacia. In this case the cystic lesions are located above the frontal horns (Fig. 15). These lesions are typical of the premature neonate and develop as a consequence of necrosis with matter due to a hypoxicischemic event. Sometimes they develop in utero and in this case the prognosis is extremely poor, since cystic periventricular leukomalacia is considered the most predictive sign of cerebral palsy.

\section{VEIN OF GALEN ANEURYSMATIC MALFORMATION}

Thisisa complex arteriovenous mal formation, characterized by multiple vascular communications between the vein of Galen system and cerebral arteries (carotid or basilar arteries).
The prenatal diagnosis is usually late, since the vascular lesion shows a progressive increase in size with the progression of pregnancy. It appears as a supratentorial tubular anechoic structure located in the midline above the cerebellum. The color Doppler shows a typical turbulent flow $^{21}$ (Figs 16A and B ). Possible complications of such an abnormal flow are:

- Cardiacfailure, cardiomegaly, hepatomegaly, hydrops and polyhydramnios as a consequence of the left/right shunt

- Ventriculomegaly secondary to venous hypertension or compression of the ventricular system

- Cerebral atrophy secondary to decreased blood flow to the brain parenchyma.

In the presence of such complications the prognosis is poor. In isolated cases a postnatal embolization may be planned with good results. ${ }^{22}$ 


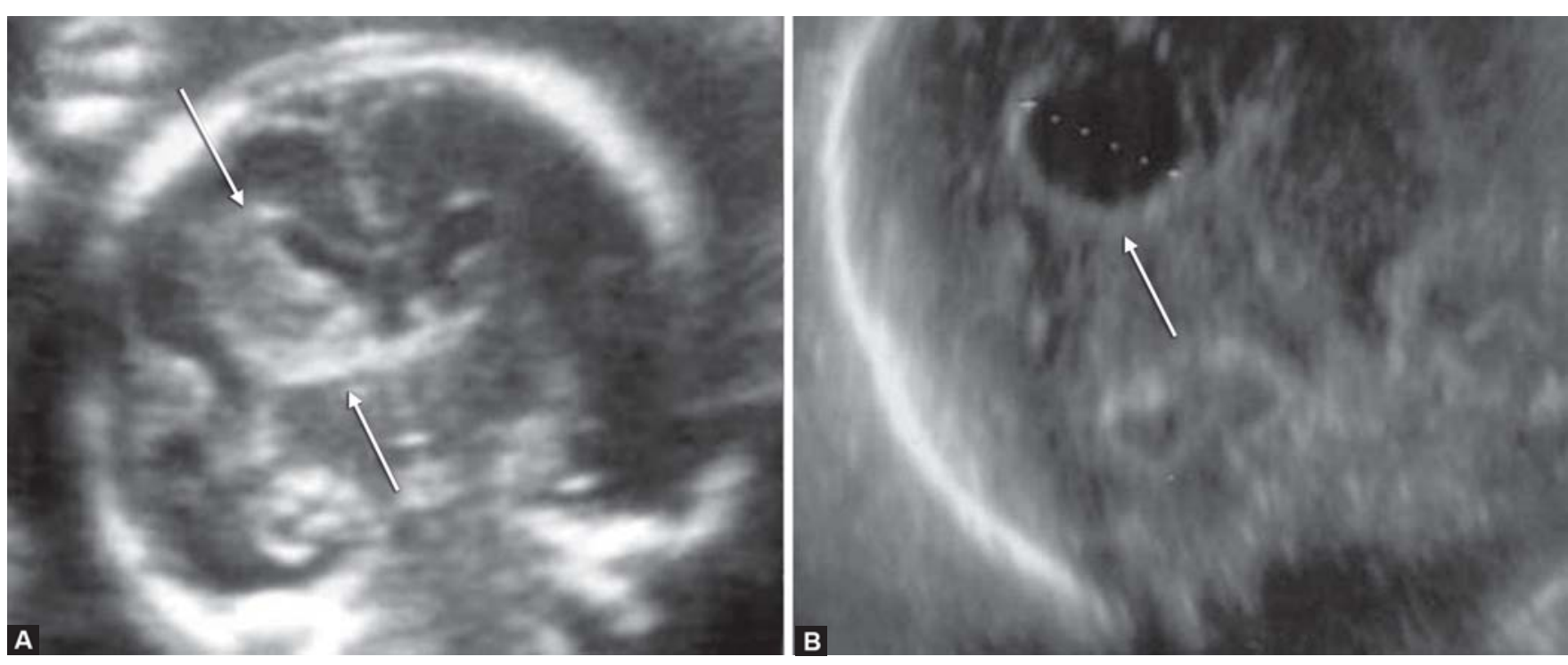

Figs 17A and B: Intraparenchymal hemorrhage: the fresh hemorrhage appears as an area of increased echogenicity in the periventricular area (A). After some weeks a colliquation occurred and the sonographic finding is that of a cystic area with hyperechoic walls (B)
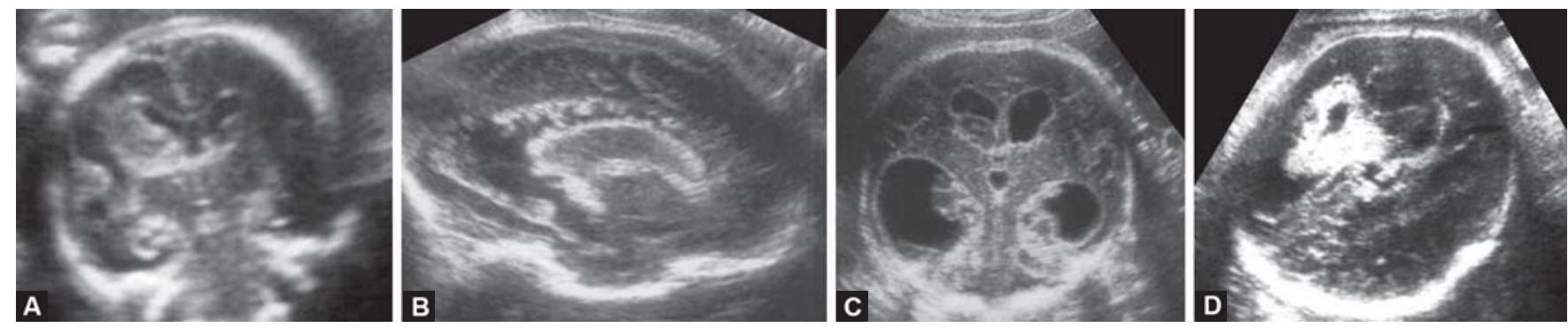

Figs 18A to D: Different grades of peri/intraventricular hemorrhages: (A) grade I: limited to the subependymal matrix; (B) grade II: intraventricular bleeding without ventriculomegaly; (C) grade III: intraventricular bleeding with ventriculomegaly; (D) grade IV: bleeding also in the periventricular parenchyma

\section{HEMORRHAGES}

Hemorrhages are rare events in the fetus. As well as in neonates they are mainly due to altered intracranial blood flow and pressure, secondary to hypoxia/hypercapnia, eventually associated with cardiac failure. ${ }^{23}$ This may happen in severe intrauterine growth restriction, particularly when complicated by placental abruption. Other conditions in which brain hemorrhage may develop are the twin-totwin transfusion syndrome in monochorionic twins (particularly after the death of a cotwin with consequent high and sudden variations of the blood pressure), severe fetal anemia, intrauterine infections, alloimmune thrombocytopenia, von Willebrand disease.

The sonographic features of intracranial hemorrhages changes according to the location of the bleeding and the time interval between the hemorrhage and the first ultrasonic examination. ${ }^{24} \mathrm{~A}$ fresh intraparenchymal hemorrhage appear as an area of increased echogenicity in the periventricular area. After some weeks a colliquation may occur and the sonographic finding is that of a cystic area with hyperechoic walls (Figs 17A and B). Peri/intraventricular hemorrhages show different sonographic patterns according to the severity of hemorrhage (Figs 18A to D). Four grades are reported:

Gradel: limited to the subependymal matrix

Grade II: Intraventricular bleeding without ventriculomegaly

GradeIII: Intraventricular bleeding with ventriculomegaly

Grade IV: Grades I, II or III with bleeding also in the periventricular parenchyma.

The prognosis is extremely variable: the fetus may die in utero, the hemorrhage may evolve in periventricular leukomalacia, but small hemorrhages may resolve without any sequela.

\section{REFERENCES}

1. Grandjean $H$, Larroque $D$, Levi S. The performance of routine ultrasonographic screening of pregnancies in the Eurofetus Study. A m J Obstet Gynecol 1999 A ug;181(2):446-454.

2. M alinger $G$, Lerman-Sagie T, W atemberg $N$, Rotmensch S, L ev D, Glezerman M. A normal second-trimester ultrasound does not exclude intracranial structural pathology. U Itrasound Obstet Gynecol 2002 Jul;20(1):51-56. 
Late Onset Brain Anomalies: Tumors, Cysts and Hemorrhages

3. Oi S, K okunai T, M atsumoto S. Congenital brain tumors in J apan (ISPN Cooperative Study): Specific clinical features in neonates. Childs Nerv Syst 1990 M ar;6(2):86-91.

4. Isaacs H. Perinatal brain tumors: a review of 250 cases. Pediatr Neurol 2002 N ov;27(5):249-261.

5. Parmar HA, Pruthi S, Ibrahim M, Gandhi D. Imaging of congenital brain tumors. Semin Ultrasound CT MR 2011 Dec;32(6):578-589.

6. Cassart M, Bosson N, G arel C, Eurin D, A vni F. Fetal intracranial tumors: a review of 27 cases. Eur Radiol 2008 Oct;18(10): 2060-2066.

7. Sahin FK, Koken G, Cosar E, K oken R, Sahin O, Gokden M. A prenatal diagnosed case of primitive neuroectodermal tumor. Fetal Diagn Ther 2008;23(4):267-270.

8. Pinto V , M eo F, L oiudice L, D 'A ddario V. Prenatal sonographic imaging of an immature intracranial teratoma. Fetal Diagn Ther 1999 J ul-A ug; 14(4):220-222.

9. A nselem $O, M$ ezzetta $L, G$ rangé $G$, Zerah $M, B$ enard $C, M$ arcou V, Fallet-Bianco C, A damsbaum C, T satsaris V. Fetal tumors of the choroid plexus: is differential diagnosis between papilloma and carcinoma possible? Ultrasound Obstet Gynecol 2011 Aug;38(2):229-232.

10. Ickowitz V, Eurin D, Rypens F, Sonigo P, Simon I, David P, B runelle $F$, A vni FE. Prenatal diagnosis and postnatal followup of pericallosal lipoma: report of seven new cases. AJNR A m J Neuroradiol 2001 A pr;22(4):767-772.

11. D'A ddario $V$, Pinto $V, M$ eo $F$, Resta $M$. The specificity of ultrasound in the detection of fetal intracranial tumors. J Perinat M ed 1998;26(6):480-485.

12. Westermaier $\mathrm{T}$, Schweitzer $\mathrm{T}$, Ernestus RI. A rachnoid cysts. Adv Exp M ed Biol 2012;724:37-50.

13. Chen CP. Prenatal diagnosis of arachnoid cysts. Taiwan J O bstet Gynecol 2007 Sep;46(3):187-198.

14. Haino K, Serikawa T, Kikuchi A, Takakuwa K, Tanaka K. Prenatal diagnosis of fetal arachnoid cyst of the quadrigeminal cistern in ultrasonography and MRI. Prenat Diagn 2009 Nov;29(11):1078-1080.

15. D'A ddario V, Pinto V, Rossi AC, Pintucci A, Di Cagno L. Cavum veli interpositi cyst: prenatal diagnosis and postnatal outcome. Ultrasound Obstet Gynecol 2009 J ul;34(1):52-54.

16. Gedikbasi A, Palabiyik F, Oztarhan A, Y ildirim G, Eren C, Ozyurt SS, Ceylan $Y$. Prenatal diagnosis of a suprasellar arachnoid cyst with 2- and 3-dimensional sonography and fetal magnetic resonance imaging: difficulties in management and review of the literature. J Ultrasound Med 2010 Oct;29(10): 1487-1493.

17. Gandolfi Colleoni G, Contro E, Carletti A, Ghi T, Campobasso $G$, Rembouskos G, V olpe G, Pilu G, V ol peP. Prenatal diagnosis and outcome of fetal posterior fossa fluid collections. U Itrasound Obstet Gynecol 2012 J un;39(6):625-631.

18. Bannister CM, Russell SA, Rimmer S, M owle DH. Fetal arachnoid cysts: their site, progress, prognosis and differential diagnosis. Eur J Pediatr Surg 1999 Dec;9 Suppl 1:27-28.

19. Bats AS, M olho M, Senat M V, Paupe A, B ernard JP, V ille Y. Subependymal pseudocysts in the fetal brain: prenatal diagnosis of two cases and review of the literature. Ultrasound Obstet Gynecol $2002 \mathrm{Nov} ; 20(5): 502-505$.

20. D'A ddario V, Selvaggio $S$, Pinto $V$, Resta $M$, Di Cagno L, Famà A. Fetal subependymal cysts with normal neonatal outcome. A case report. Fetal Diagn Ther 2003 M ay-J un; 18(3):170-173.

21. Has R, G ünay S, I brahimoglu L. Prenatal diagnosis of a vein of Galen aneurysm. Fetal Diagn Ther 2003 J an-Feb;18(1):36-40.

22. B runelleF. B rain vascular malformations in the fetus: diagnosis and prognosis. Childs Nerv Syst 2003 A ug;19(7-8):524-528.

23. Sherer DM, A nyaegbunam A, Onyeije C. A ntepartum fetal intracranial hemorrhage, predisposing factors and prenatal sonography: a review. A m J Perinatol 1998 J ul;15(7):431-441.

24. Ghi T, Simonazzi G, Perolo A, Savelli L, Sandri F, B ernardi B, Santini D, B ovicelli L, Pilu G. Outcome of antenatally diagnosed intracranial hemorrhage: case series and review of the literature. Ultrasound Obstet Gynecol 2003 A ug;22(2):121-123.

\section{ABOUT THE AUTHORS}

\section{Vincenzo D'Addario (Corresponding Author)}

Associate Professor, Department of Obstetrics and Gynecology University of Bari, Italy, e-mail: vincenzo.daddario@uniba.it

\section{Pasquale Capuano}

Resident, Department of Obstetrics and Gynecology, U niversity of Bari, Italy

\section{Grazia Volpe}

Resident, Department of Obstetrics and Gynecology, U niversity of Bari, Italy 